\title{
O PERFIL DOS PRODUTORES DE ARROZ DO VALE DO RIO PARDO- RS E O PROCESSO DE GESTÃO RURAL
}

\author{
Ricardo Tatsch ${ }^{1}$ \\ Cidonea Machado Deponti
}

\begin{abstract}
RESUMO
A dinâmica da globalização e a incorporação de novas tecnologias no meio rural obrigaram os produtores a se adequarem às novas exigências, entre elas, a inclusão de práticas contábeis e gerenciais, fundamentais para se conseguir eficiência nas propriedades rurais. Com base nessa premissa, pretendeu-se, caracterizar o perfil dos produtores de arroz do Vale do Rio Pardo-RS e verificar o uso de instrumentos contábeis para controle da atividade. Buscou-se, também, demonstrar a importância do cultivo do arroz, como uma alternativa de produção em uma região em que o foco está no tabaco, trazendo informações relevantes sobre a área cultivada, a produção e a produtividade das lavouras em níveis nacional, estadual e regional. Trata-se de uma pesquisa exploratória, com uma breve revisão bibliográfica, com utilização de dados secundários e com a aplicação de questionário, por telefone. Acessou-se 37 dos 63 orizicultores do município de Rio Pardo-RS, segundo maior produtor de arroz da região. Além de dados referentes ao perfil dos produtores, observou-se que apenas $43 \%$ dos entrevistados mantêm alguma forma de controle e apenas um deles foi capaz de responder sobre o custo de produção por hectare. Deve-se, portanto, levar em conta toda a diversidade existente, seja de idade, escolaridade, conhecimento técnico, infraestrutura existente, domínio da área, financiamento da lavoura, entre outros. Concluiu-se que é preciso considerar a diversidade, as diferentes capacidades e formas de ação, os vastos conhecimentos que eles trazem consigo. Além de compreender a percepção que eles têm sobre a necessidade de conhecimento técnicos e gerenciais para o sucesso do seu negócio.
\end{abstract}

Palavras-chave: contabilidade rural, gestão rural, desenvolvimento regional, produtor de arroz.

\section{THE PROFILE OF RICE PRODUCERS IN THE VALLEY OF RIO PARDO-RS AND THE RURAL MANAGEMENT PROCESS}

\section{ABSTRACT}

The dynamics of globalization and the incorporation of new technologies in the rural environment have forced producers to adapt to new demands, among them, the

\footnotetext{
${ }^{1}$ Graduação em Agronomia (UFSM). MBA em Administração em Agronegócios e Biotecnologia (UNINTER). Mestrado em Desenvolvimento Regional da Universidade de Santa Cruz do Sul (PPGDR/UNISC). E-mail: ricardotatsch@gmail.com

2 Graduação em Ciências Econômicas (UFSM). Mestrado em Mestrado em Integração Latino-Americana (UFSM). Doutorado em Desenvolvimento Rural (UFRGS). Professora do Programa de Pós-Graduação em Desenvolvimento Regional da Universidade de Santa Cruz do Sul (PPGDR/UNISC). E-mail: cidonea@unisc.br
} 
inclusion of accounting and management practices, essential to achieve efficiency in rural properties. Based on this premise, it was intended to characterize the profile of rice producers in Vale do Rio Pardo-RS and verify the use of accounting instruments to control the activity. It was also sought to demonstrate the importance of rice farming, as an alternative production in a region where the focus is on tobacco, bringing relevant information about the cultivated area, production and productivity of crops at national, state and regional levels. This is an exploratory research, with a brief literature review, using secondary data and applying a questionnaire by telephone. We accessed 37 of the 63 rice farmers in the municipality of Rio Pardo-RS, second largest rice producer in the region. Besides data relating to the profile of producers, it was observed that only $43 \%$ of respondents maintain some form of control and only one of them was able to answer about the cost of production per hectare. Therefore, it is necessary to take into account all the existing diversity, whether of age, education, technical knowledge, existing infrastructure, mastery of the area, financing of farming, among others. It was concluded that it is necessary to consider the diversity, the different capacities and forms of action, the vast knowledge they bring with them. In addition to understanding the perception they have about the need for technical and managerial knowledge for the success of their business.

Keywords: rural accounting, rural management, regional development, rice producer.

\section{INTRODUÇÃO}

O setor orizícola é muito importante para o Vale do Rio Pardo, seja pela geração de empregos diretos e indiretos, giro de recursos financeiros na economia local, bem como pela utilização do comércio e prestação de serviço. Assim, torna-se relevante conhecer e caracterizar esse ramo produtivo, principalmente no que se refere às dificuldades encontradas pelos produtores de arroz em manter suas atividades. Uma vez que a alta tecnologia envolvida no processo produtivo faz com que haja um crescimento no custo dessa produção, sendo necessário um maior controle dos gastos para que seja possível dar continuidade e sustentabilidade à atividade.

A questão colocada como elemento de investigação nesse artigo está situada na caracterização dos orizicultores do município de Rio Pardo, localizado na região do Vale do Rio Pardo, centro do estado do Rio Grande do Sul. Buscou-se compreender os elementos fundamentais para sua sustentabilidade no meio rural e, consequentemente, no desenvolvimento da região como um todo. Essa região é reconhecida pela produção de tabaco e pela imigração europeia que deixaram suas marcas sobre esse território (ETGES, 2001). A produção do arroz não é, portanto, predominante, mas se apresenta como uma alternativa importante para o desenvolvimento rural.

Assim, apesar da importância da produção agrícola para a região, verifica-se uma lacuna no que se refere à rentabilidade e consequente à manutenção destes produtores de arroz em sua atividade. Através de um simples cruzamento de informações realizado pelos autores, utilizando os dados de produtividade média dos orizicultores do Rio Grande do Sul, do custo de produção médio anual calculado pelo IRGA e de valores pagos aos produtores pela saca de arroz nas últimas dez safras $2008 / 2009$ até $2017 / 2018$-, chega-se ao resultado que os orizicultores obtiveram renda em apenas quatro destas últimas dez safras agrícolas. Nas demais seis safras a sua produção não foi suficiente para cobrir os custos fixos e/ou, nem os variáveis, 
ficando com resultado negativo, causando endividamento, sucateamento do maquinário, redução na qualidade de vida e êxodo rural.

A utilização de técnicas de gestão poderá minimizar algumas das problemáticas que perpassam o desenvolvimento rural, proporcionando um melhor controle, redução dos custos de produção, maior competitividade e, consequentemente, a manutenção destes produtores e sua família na atividade. A bibliografia indica que é mínima a utilização de técnicas de gestão pelos produtores rurais (CREPALDI, 2006; BATALHA; SCARPELLI, 2002; DEPONTI, 2014). Resultados semelhantes se apresentam entre os orizicultores da Região do Vale do Rio Pardo, conforme levantamento preliminar (TATSCH; DEPONTI, 2017).

Apesar de pouco utilizarem-se de "técnicas contábeis" na gestão de suas propriedades estes produtores de arroz vêm, de uma forma ou outra, gerindo sua unidade produtiva e mantêm-se ativos no meio rural. Sendo assim, é importante compreender como se dá a dinâmica de interação entre controles econômicos e financeiros e o processo de gestão rural dessas propriedades.

Trabalhos existentes até o momento sobre gestão rural, encontrados na literatura, trazem em sua problemática questões como a falta de adesão às técnicas de gestão pelos produtores rurais, demonstrativos de resultados, controles econômico-financeiros, etc. Enfim, cabe compreender a importância da gestão de propriedades rurais, como é apresentada na literatura recente sobre a questão. Assim, é possível verificar que a adoção de algumas técnicas pode contribuir para o desenvolvimento rural, não deixando de considerar que essas técnicas serão adaptadas, transformadas e - quiçá - aprimoradas pelo conhecimento prático dos atores que influenciam em sua adoção (BATALHA; SCARPELLI, 2002; BORILLI et al., 2005; DEPONTI, 2014).

Por isso, considera-se importante analisar a forma como vêm sendo gerenciadas essas propriedades orizícolas. Para tanto, fez-se necessário uma revisão da literatura e o levantamento de dados secundários sobre a produção, a área colhida e a produtividade do arroz em níveis municipal, regional, estadual e federal, obtidos nos seguintes institutos CONAB (2018); FEE (2015); IBGE (2017); IRGA (2018); USDA/FAZ (2018). Também, observou-se a produção e o consumo do arroz no Brasil, em que se verificou a importância desse cereal para o cenário nacional (CONAB, 2016). Utilizou-se os dados do censo da lavoura de arroz do IRGA (2006). A utilização dos dados com base no Censo do IRGA justifica-se, porque não há os mesmos dados no Censo Agropecuário de 2017, considerado bastante incompleto quando comparado com os dados do IRGA (2006).

Além disso, contatou-se, por telefone, 63 orizicultores do município de Rio Pardo-RS, dos quais 37 foram localizados. As perguntas envolveram questões relativas à propriedade da terra, ao uso da mão de obra, ao tempo de experiência na atividade, à escolaridade, ao acesso a informações via Internet e, por fim, à forma como se dá a gestão dessas propriedades.

O presente artigo está dividido em três seções, além dessa introdução e da conclusão. A primeira seção discute sobre a importância dos controles gerenciais e econômicos na gestão das propriedade rurais. A segunda apresenta a produção de arroz no Brasil, no Rio Grande do Sul e no Vale do Rio Pardo. E, a terceira seção discute os dados relacionados ao perfil dos orizicultores no município de Rio Pardo e suas relações com o processo de gestão rural. 


\section{A IMPORTÂNCIA DA GESTÃO ECONÔMICO-FINANCEIRA NAS PROPRIEDADES RURAIS}

Crepaldi (2006) conceitua gestão rural como um conjunto de atividades que auxiliam os agricultores em sua tomada de decisão a fim de melhorarem a rentabilidade de seu negócio, mantendo-os na atividade. Afirma que a contabilidade rural é um dos principais sistemas de controle e de informação para os agricultores. Ela pode orientar as operações agrícolas, medir o desempenho econômico-financeiro das atividades, controlar as transações financeiras, apoiar a tomada de decisão no planejamento da produção, vendas e investimentos. Além disso, contribui ao auxiliar nas projeções de fluxos de caixa, comparar o desempenho ao longo do tempo, orientar as despesas pessoais e gerar informações para a declaração do Imposto de Renda.

Apesar disso, trata-se de uma das ferramentas administrativas menos utilizadas pelos produtores brasileiros, por ser vista como uma técnica complexa em sua execução e de baixo retorno na prática, servindo apenas para fins fiscais. A pouca utilização justifica-se devido ao desconhecimento por parte dos agricultores da importância que as informações obtidas trazem para a tomada de decisões. Crepaldi (2006; 2009) salienta ainda que há uma mentalidade conservadora por grande parte dos produtores, que continuam utilizando controles baseados em sua experiência adquirida com o passar dos anos.

Na mesma linha, Callado (2009) destaca a importância da gestão rural para uma tomada de decisão eficiente e coloca a contabilidade como prestadora de serviços aos agricultores nos aspectos que se referem à formulação, reformulação ou avaliação dos processos administrativos e produtivos, utilizada para atingir os fins produtivos e sociais da empresa. Atribui ao administrador rural atividades relacionadas ao planejamento, controle, decisão e avaliação dos resultados, tendo sempre em vista, além da maximização dos resultados, o bem estar dos empregados.

Em meio à evolução tecnológica, com novos processos e um ambiente cada vez mais competitivo, com altos custos de produção e margem de lucros cada vez mais apertada, o produtor rural tem buscado ganhos contínuos de eficiência com redução de custos, aumento de produtividade e diferenciação de produtos. Há, porém, vários casos em que o agricultor não realiza um controle de custos de produção, perdendo competitividade perante o mercado e, muitas vezes, tendo que abandonar o negócio.

A contabilidade e as técnicas de gestão são recursos que auxiliam na tomada de decisão dos produtores rurais. Para Callado et al. (2007), a contabilidade não deve se limitar a fatores financeiros, mas, sim, auxiliar nos processos administrativos e produtivos, facilitando as escolhas que produzam o melhor resultado. Conforme Crepaldi (1998), necessitamos de uma atualização dos meios de gerenciamento das empresas rurais para alcançar resultados de produção e de produtividade que garantam o sucesso do empreendimento. Através de tecnologias que permitam interligar criações, pode ser possível obter rendimentos adicionais, diluir custos e economizar insumos.

Já em outra perspectiva, Pelegrini e Gazolla (2008, p. 155) conceituam a gestão rural como um:

[...] processo em que o agricultor administra da melhor forma possível o seu empreendimento, combinando, para isso, os recursos disponíveis como a força de trabalho familiar, os recursos econômicos, os conhecimentos técnico-produtivos, o capital social, os seus recursos naturais, etc. para obter os 
melhores resultados e desenvolver de forma sustentável a sua unidade de produção e de processamento de alimentos.

Ou seja, de acordo com os autores Pelegrini e Gazolla (2008), a gestão rural é compreendida como a utilização de técnicas e de conhecimentos que permitam ao produtor rural gerir da melhor maneira possível os seus recursos, ampliando a rentabilidade e a sustentabilidade de sua propriedade.

Considerando o exposto sobre gestão, considera-se importante ressaltar que a gestão rural compreende um processo complexo de interação entre controles e decisões tomadas pelo agricultor dentro da propriedade, em todas as dimensões, num conjunto de relações familiares. E não somente um processo baseado em controles financeiros ou então à utilização de técnicas contábeis. Não será possível, neste trabalho, analisar todas as dimensões da gestão. Porém, aqui, vale destacar que esta tomada de decisão por parte dos agricultores não é unidirecional, e buscar-se-á compreender a percepção dos produtores de como essa multidimensionalidade interfere em sua tomada de decisão.

Entende-se, portanto, que o controle de custos e a gestão econômica e financeira não garantem desenvolvimento rural, sendo uma entre as dimensões representadas pela tríade social, econômica e ambiental. Entretanto, pode ser uma dimensão de melhoria da visão dos agricultores para um olhar mais abrangente das atividades agrícolas e para o desenvolvimento de organizações rurais. Com a evolução da gestão, teremos um produtor com uma visão emancipada do seu negócio, numa análise econômica, ambiental e social, para um desenvolvimento interdisciplinar (BRANDÃO, 2011; FONTOURA E WITTIMANN, 2016; LENCIONI, 1999).

Assim, para pensar a gestão sobre essa perspectiva, é preciso considerar não apenas as técnicas estabelecidas e reproduzidas em institutos e universidades. É preciso considerar a importância que essa tem para os atores e a forma como eles a realizam em suas propriedades, ainda que essa não seja considerada científica. Também é preciso considerar que o paradigma da modernização, a industrialização e a globalização afetaram a forma como se dá o fazer no cotidiano dos trabalhadores rurais. A evolução tecnológica trouxe novos processos e um ambiente cada vez mais competitivo, com altos custos de produção e uma margem de lucros cada vez mais apertada. Nesse contexto, o produtor rural deve considerar a redução de custos, o aumento de produtividade e a diferenciação de produtos.

A interligação entre a literatura advinda da administração mostra que é necessário pensar o processo de gestão sob a perspectiva dos atores envolvidos, pois somente o controle de custos e a gestão econômica e financeira não garantem desenvolvimento rural. Entretanto, em uma sociedade capitalista, a sustentabilidade financeira também é importante para manter o produtor rural no campo, ampliando sua qualidade de vida. A gestão pode, inclusive, ser uma forma de empoderar os agricultores, ampliando seu olhar sobre as atividades agrícolas, incentivando o desenvolvimento de organizações rurais (BRANDÃO, 2011; FONTOURA; WITTIMANN, 2016).

Portanto, espera-se que os resultados dos processos de gestão rural possibilitem a agregação de diversas formas de conhecimento que são cotidianamente produzidas com os controles econômicos e financeiros levando a maior autonomia na tomada de decisão dos produtores. 


\section{A PRODUÇÃO DE ARROZ NO BRASIL, NO RIO GRANDE DO SUL E NO VALE DO RIO PARDO}

Nesta seção levanta-se algumas questões que demonstram a importância da produção de arroz em nível nacional, estadual e regional, dando um panorama geral do cenário atual e de sua transformação nos últimos 15 anos.

O arroz é o segundo cereal mais cultivado no mundo, totalizando 162,4 milhões de hectares, com uma produção de 504,2 milhões de toneladas (USDA/FAS, 2021). E está entre os mais consumidos no mundo, sendo o principal alimento de mais da metade da população. No Brasil, responsável por 76\% da produção do Mercosul, é produzido em vários estados, com uma grande concentração no Sul, especialmente no Rio Grande do Sul. Esse é o responsável por $77 \%$ da produção nacional (CONAB, 2020) em uma área de 946,4 mil hectares, correspondentes a aproximadamente $73 \%$ da área de cultivo nacional, predominando o sistema irrigado.

Introduzido no Brasil por Pedro Álvares Cabral, tendo o relato de seu cultivo a partir de 1530 na capitania de São Vicente, o arroz se espalhou por regiões do litoral, sempre em pequenas lavouras de subsistência. Em 1904 surgiu a primeira lavoura empresarial, no município de Pelotas-RS, logo após chegou à Cachoeira do Sul, intitulada como a capital nacional do arroz irrigado. Ganhou impulso com a vinda dos locomoveis, que tocavam as bombas de irrigação, facilitando a inundação das lavouras (PEREIRA, 2002).

A Figura 01 demonstra a distribuição das lavouras de arroz no Brasil, cereal que representa cerca de $20 \%$ do total de grãos colhidos, é especialmente forte no Sul do País, mais especificamente na metade sul do Rio Grande do Sul, Estado que cultivou 1.088.096 hectares na safra 2016/2017. Nas outras regiões do Brasil, ganham destaque o Maranhão, na Região Nordeste, com a maior área, 83,7 mil hectares; Mato Grosso, na Região Centro-Oeste, com 132,8 mil hectares, registrando a segunda maior área com o grão; e Tocantins, na Região Norte, com 100,1 mil hectares. A Região Sudeste possui pouca expressão no cultivo de arroz (IBGE, 2017).

Figura 1 - Mapa da concentração da produção de arroz no Brasil (toneladas)

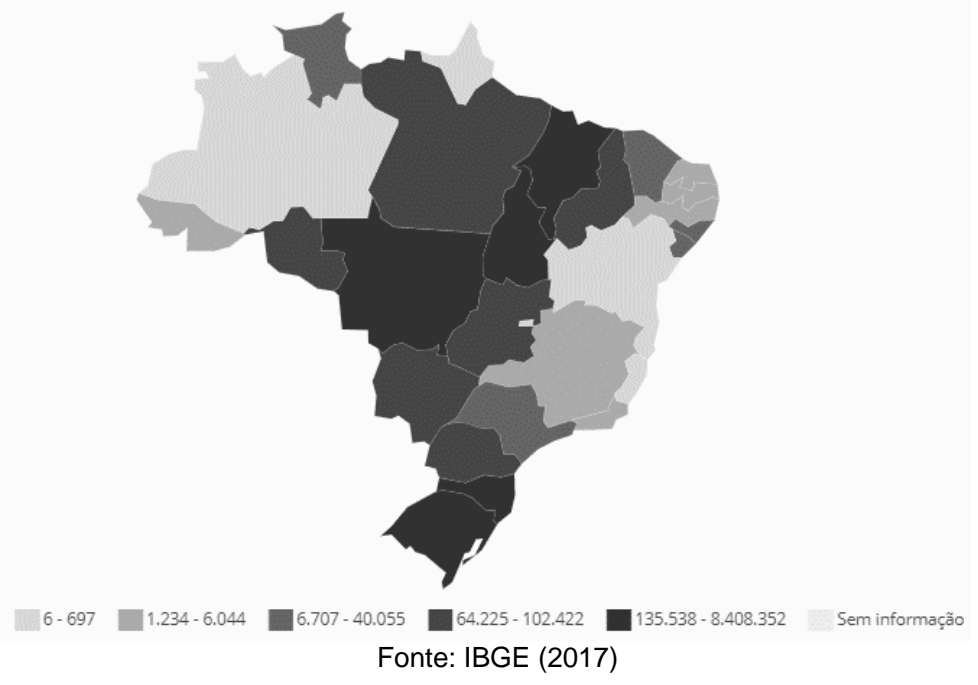


A tabela 1 apresenta uma série histórica da área de arroz plantada, nas safras de 2002/2003 a 2019/2020, em mil hectares na região Sul, RS e no Brasil.

Tabela 1 - Série histórica de área de arroz plantada, safras 2002/2003 a 2019/2020, em mil hectares na região Sul, RS e no Brasil

\begin{tabular}{cccccccccc} 
REGIÃO/UF & $\mathbf{2 0 0 2 / 0 3}$ & $\mathbf{2 0 0 3 / 0 4}$ & $\mathbf{2 0 0 4 / 0 5}$ & $\mathbf{2 0 0 5 / 0 6}$ & $\mathbf{2 0 0 6 / 0 7}$ & $\mathbf{2 0 0 7 / 0 8}$ & $\mathbf{2 0 0 8 / 0 9}$ & $\mathbf{2 0 0 9} / \mathbf{1 0}$ & $\mathbf{2 0 1 0 / 1 1}$ \\
\hline REGIÃO SUL & $1.174,8$ & $1.255,9$ & $1.266,6$ & $1.257,9$ & $1.167,6$ & $1.266,9$ & $1.299,0$ & $1.270,4$ & $1.361,5$ \\
\hline RS & 960,4 & $1.039,2$ & $1.049,6$ & $1.039,7$ & 954,4 & $1.066,6$ & $1.105,6$ & $1.079,6$ & $1.171,6$ \\
\hline BRASIL & $3.186,1$ & $3.654,4$ & $3.916,3$ & $3.017,8$ & $2.967,4$ & $2.875,0$ & $2.909,0$ & $2.764,8$ & $2.820,3$ \\
\hline
\end{tabular}

\begin{tabular}{cccccccccc} 
REGIÃO/UF & $\mathbf{2 0 1 1 / 1 2}$ & $\mathbf{2 0 1 2 / 1 3}$ & $\mathbf{2 0 1 3} / \mathbf{1 4}$ & $\mathbf{2 0 1 4} / \mathbf{1 5}$ & $\mathbf{2 0 1 5 / 1 6}$ & $\mathbf{2 0 1 6 / 1 7}$ & $\mathbf{2 0 1 7 / 1 8}$ & $\mathbf{2 0 1 8} / \mathbf{1 9}$ & $\mathbf{2 0 1 9 / 2 0}$ \\
\hline REGIÃO SUL & $1.238,9$ & $1.249,7$ & $1.299,9$ & $1.295,2$ & $1.273,2$ & $1.249,6$ & 1228,2 & 1129,2 & 1101,4 \\
\hline RS & $1.053,0$ & $1.066,6$ & $1.120,1$ & $1.120,1$ & $1.100,7$ & $1.088,1$ & $1.066,1$ & 964,5 & 936,3 \\
\hline BRASIL & $2.426,7$ & $2.399,6$ & $2.372,9$ & $2.295,1$ & $1.954,5$ & $1.980,9$ & $1.972,1$ & $1.702,5$ & $1.665,8$ \\
\hline
\end{tabular}

Fonte: CONAB, 2020.

Como é possível observar na Tabela 01, na safra de 2002/2003 a região sul foi responsável por 36,9\% das áreas destinadas ao cultivo de arroz do Brasil, sendo 30,1\% concentradas no RS. Já em 2019/2020, com a grande redução de área nas demais regiões brasileiras, a área orizícola da região sul representou $66 \%$ do total nacional, sendo $56 \%$ concentradas nesse Estado. 
Tabela 2 - Série histórica da produção de arroz, safras 2002/2003 a 2019/2020, em mil toneladas, na região Sul, RS e no Brasil

\begin{tabular}{cccccccccc} 
REGIÃO/UF & $\mathbf{2 0 0 2 / 0 3}$ & $\mathbf{2 0 0 3 / 0 4}$ & $\mathbf{2 0 0 4 / 0 5}$ & $\mathbf{2 0 0 5 / 0 6}$ & $\mathbf{2 0 0 6 / 0 7}$ & $\mathbf{2 0 0 7 / 0 8}$ & $\mathbf{2 0 0 8 / 0 9}$ & $\mathbf{2 0 0 9 / 1 0}$ & $\mathbf{2 0 1 0 / 1 1}$ \\
\hline REGIÃO SUL & $5.920,1$ & $7.607,1$ & $7.533,0$ & $8.152,2$ & $7.697,7$ & $8.552,8$ & $9.116,4$ & $8.547,0$ & $10.091,1$ \\
\hline RS & $4.696,4$ & $6.432,7$ & $6.332,9$ & $6.872,4$ & $6.419,3$ & $7.361,7$ & $7.905,0$ & $7.320,8$ & $8.904,2$ \\
\hline BRASIL & $10.367,1$ & $12.960,4$ & $13.355,0$ & $11.721,7$ & $11.315,9$ & $12.074,0$ & $12.602,5$ & $11.660,9$ & $13.613,1$ \\
\hline REGIÃO/UF & & & & & & & & & \\
\hline REGIÃO SUL & $\mathbf{2 0 1 1 / 1 2}$ & $\mathbf{2 0 1 2 / 1 3}$ & $\mathbf{2 0 1 3 / 1 4}$ & $\mathbf{2 0 1 4 / 1 5}$ & $\mathbf{2 0 1 5 / 1 6}$ & $\mathbf{2 0 1 6 / 1 7}$ & $\mathbf{2 0 1 7 / 1 8}$ & $\mathbf{2 0 1 8 / 1 9}$ & $\mathbf{2 0 1 9 / 2 0}$ \\
\hline RS & $7.984,1$ & $9.132,9$ & $9.339,2$ & $9.840,7$ & $8.528,9$ & $9.762,3$ & 9729,4 & $8.489,8$ & $9.137,5$ \\
\hline BRASIL & $11.599,5$ & $11.819,7$ & $12.121,6$ & $12.444,5$ & $10.603,0$ & $12.327,8$ & $12.064,2$ & $10.483,6$ & $11.183,4$ \\
\hline
\end{tabular}

Fonte: CONAB, 2020. 
De acordo com a Tabela 02, em 2002/2003 a Região Sul foi responsável pela produção de 5,92 do total de 10,37 milhões de toneladas de arroz produzidas em todo o território brasileiro, representando $57,1 \%$ da produção. Somente o Rio Grande do Sul produziu 4,69 desse total, representando $45,3 \%$ da produção nacional. Já na safra 2019/2020, mais de $81 \%$ dessa produção se concentrou no sul do País e, $70,1 \%$ ficou por conta do Estado gaúcho.

Com os dados das TABELAS 1 e 2 é possível concluir que, apesar da redução da área de cultivo de arroz em quase $50 \%$, caindo de 3,18 para 1,65 milhões de hectares, o país apresentou um incremento na produção total do cereal, de 10,37 para 11,18 milhões de toneladas.

Este crescimento da produção brasileira deve-se, principalmente, pelo uso intensivo de tecnologias (genética e manejo), que agregam ganho em produtividade, e pela redução de área não se dar na Região Sul, que se utiliza do sistema de cultivo irrigado, com maior potencial produtivo, e sim nas demais regiões do Brasil, onde a maior parte do cultivo é realizado em sequeiro, com rendimentos mais baixos. 
Tabela 3 - Série histórica da produtividade de arroz, safras 2002/2003 a 2019/2020, em quilogramas por hectare na região Sul, RS e no Brasil

\begin{tabular}{|c|c|c|c|c|c|c|c|c|c|}
\hline REGIÃO/UF & $2002 / 03$ & $2003 / 04$ & $2004 / 05$ & $2005 / 06$ & $2006 / 07$ & $2007 / 08$ & $2008 / 09$ & $2009 / 10$ & 2010/11 \\
\hline REGIÃO SUL & $5.039,0$ & $5.953,0$ & $5.847,0$ & $6.480,8$ & $6.592,8$ & $6.751,0$ & $7.018,0$ & $6.728,0$ & $7.412,0$ \\
\hline RS & $4.890,0$ & $6.064,0$ & $5.912,0$ & $6.610,0$ & $6.726,0$ & $6.902,0$ & $7.150,0$ & $6.781,0$ & $7.600,0$ \\
\hline BRASIL & $3.254,0$ & $3.511,0$ & $3.377,0$ & $3.884,2$ & $3.813,4$ & $4.200,0$ & $4.332,0$ & $4.218,0$ & $4.827,0$ \\
\hline REGIÃO/UF & $2011 / 12$ & $2012 / 13$ & $2013 / 14$ & $2014 / 15$ & $2015 / 16$ & $2016 / 17$ & $2017 / 18$ & $2018 / 19$ & $2019 / 20$ \\
\hline REGIÃO SUL & $7.252,0$ & $7.308,0$ & $7.184,5$ & $7.597,8$ & $6.825,3$ & $7.667,5$ & $7.921,7$ & $7.518,4$ & $8.296,3$ \\
\hline RS & $7.350,0$ & $7.438,0$ & $7.243,0$ & $7.700,0$ & $6.837,0$ & $7.725,0$ & $7.949,0$ & $7.508,0$ & $8.402,0$ \\
\hline BRASIL & $4.780,0$ & $4.925,7$ & $5.108,4$ & $5.422,3$ & $5.280,3$ & $6.223,0$ & $6.118,0$ & $6.158,0$ & $6.713,0$ \\
\hline
\end{tabular}

Fonte: CONAB, 2020. 
Esse aumento na produtividade fica claro ao se observar a Tabela 03, ou quando se compara a evolução das áreas de cultivo na Tabela 01 com a evolução da produção total, na Tabela 02. Em um período de 18 anos o Rio Grande do Sul teve um pequeno aumento no tamanho da área de cultivo, porém voltou aos mesmos patamares de 2002/2003 nas últimas duas safras. Contudo a sua produção passou de 4,69 para 7,84 milhões de toneladas no mesmo período, um incremento de $67 \%$ na produção total sem aumentar área de cultivo. Ademais, é possível concluir que novas técnicas e tecnologias estão sendo implementadas, ampliando a produtividade, sem a ampliação na área dedicada ao plantio.

O Gráfico 1 ajuda a exemplificar a quantidade produzida por estado. Como se pode verificar, o Rio Grande do Sul está disparado na frente, com 76,1\% da produção nacional. É seguido por Santa Catarina, com $8,3 \%$ da produção; pelo Tocantins, com 4,6\%; e pelo Mato Grosso, com 3,9\%. A soma da produção dos demais estados representa apenas $7,1 \%$ do total.

O consumo do arroz, por sua vez, é feito por aproximadamente por $95 \%$ dos brasileiros, sendo que mais da metade desses o fazem no mínimo uma vez por dia. 0 arroz branco polido ocupa $70 \%$ da preferência nacional, outros $25 \%$ do arroz consumido é parboilizado e de 3 a $4 \%$ é consumido na forma integral (BARATA, 2005).

Gráfico 1 - Produção de arroz por Estado, safra 2016/2017

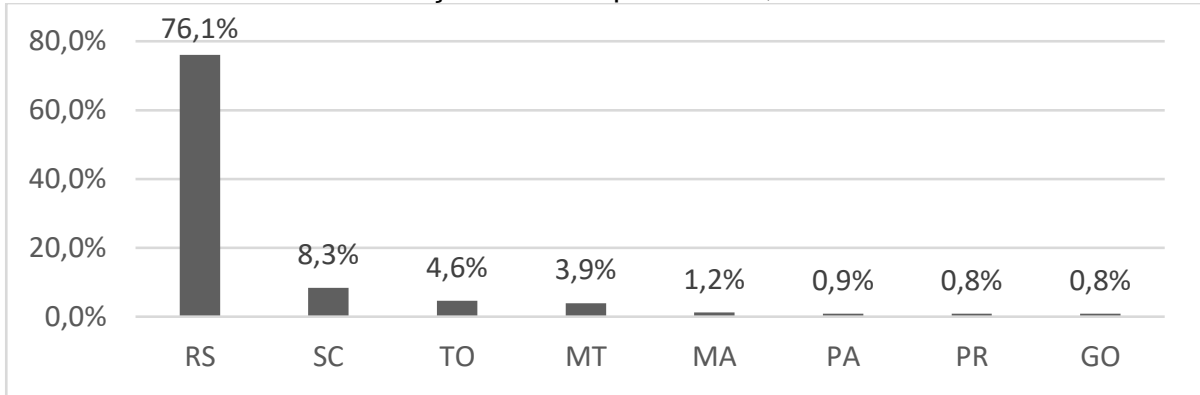

Fonte: CONAB, 2017.

O Brasil conseguiu autossuficiência na produção em 2004, embora ainda seja um importador líquido, trazendo o produto de países como Argentina, Paraguai e Uruguai, que têm um menor custo de produção. Com o passar dos anos observa-se uma redução na área de cultivo do cereal, porém um aumento da produtividade. O consumo, sem muita oscilação, tem se mantido entre 11,6 e 12 milhões de toneladas nos últimos seis anos, fazendo com que a relação entre produção e demanda venha se mantendo equilibrada (CONAB, 2016).

De acordo com o Ministério da Agricultura, Pecuária e Abastecimento (BRASIL, 2016) estima-se para 2025/2026 uma produção de 11,5 milhões de toneladas no Brasil e um consumo de 11,8 milhões de toneladas. Essa projeção da produção é baseada em uma perspectiva de redução ainda maior nas áreas de cultivo e a um aumento significativo na produtividade. Busca-se alcançar 11 toneladas por hectare, bem acima da média brasileira atual, que é 6,7 toneladas/hectare, e até mesmo da gaúcha, situada em 8,4 toneladas por hectare (CONAB, 2020).

Essa redução nas áreas de cultivo de arroz deve-se a sua baixa rentabilidade em comparação com outras culturas, como a soja, o milho ou o algodão. Até mesmo no Rio Grande do Sul, onde o produto é tradicionalmente cultivado em áreas úmidas e de difícil drenagem - próprias para o seu cultivo - ele tem perdido espaço para 
outras culturas, como a soja em rotação. Essa acaba sendo benéfica para o cultivo de arroz subsequente, trazendo ganhos de produtividade.

O Vale do Rio Pardo, localizado na encosta do planalto meridional riograndense, é formado por 23 municípios (FIGURA 02) e compreende uma área de $13.172 \mathrm{~km}^{2}$ com uma população de 434 mil habitantes, composta de descendentes de origem alemã no norte e açoriana ao sul. Tem grande importância em nível estadual principalmente nas exportações. Em 2010 a região foi responsável por 11,4\% das exportações totais do Rio Grande do Sul, e responsável por 3,98\% do Valor Agregado Bruto (VAB) do Estado (FEE, 2015).

Segundo Bertê (2016) o VAB da região do Vale do Rio Pardo é composto em $13 \%$ pela agropecuária, $29 \%$ da indústria e $57,4 \%$ de serviços, indicando uma maior participação da agropecuária e da indústria e menor dos serviços, quando comparado à média estadual; é responsável por $5,9 \%$ do VAB da agropecuária do Estado. São formadores do VAB da região o fumo e, em menor proporção, a mandioca, com $53 \%$. A criação de bovinos de leite e de corte somam 12,4\%. O cultivo de arroz e de trigo, em menor proporção, totalizam 12\%. A silvicultura e a exploração florestal, o cultivo de soja, a criação de aves e suínos, entre outros de menor expressão compõe os $22,6 \%$ restantes.

Figura 2 - Mapa da região do Vale do Rio Pardo

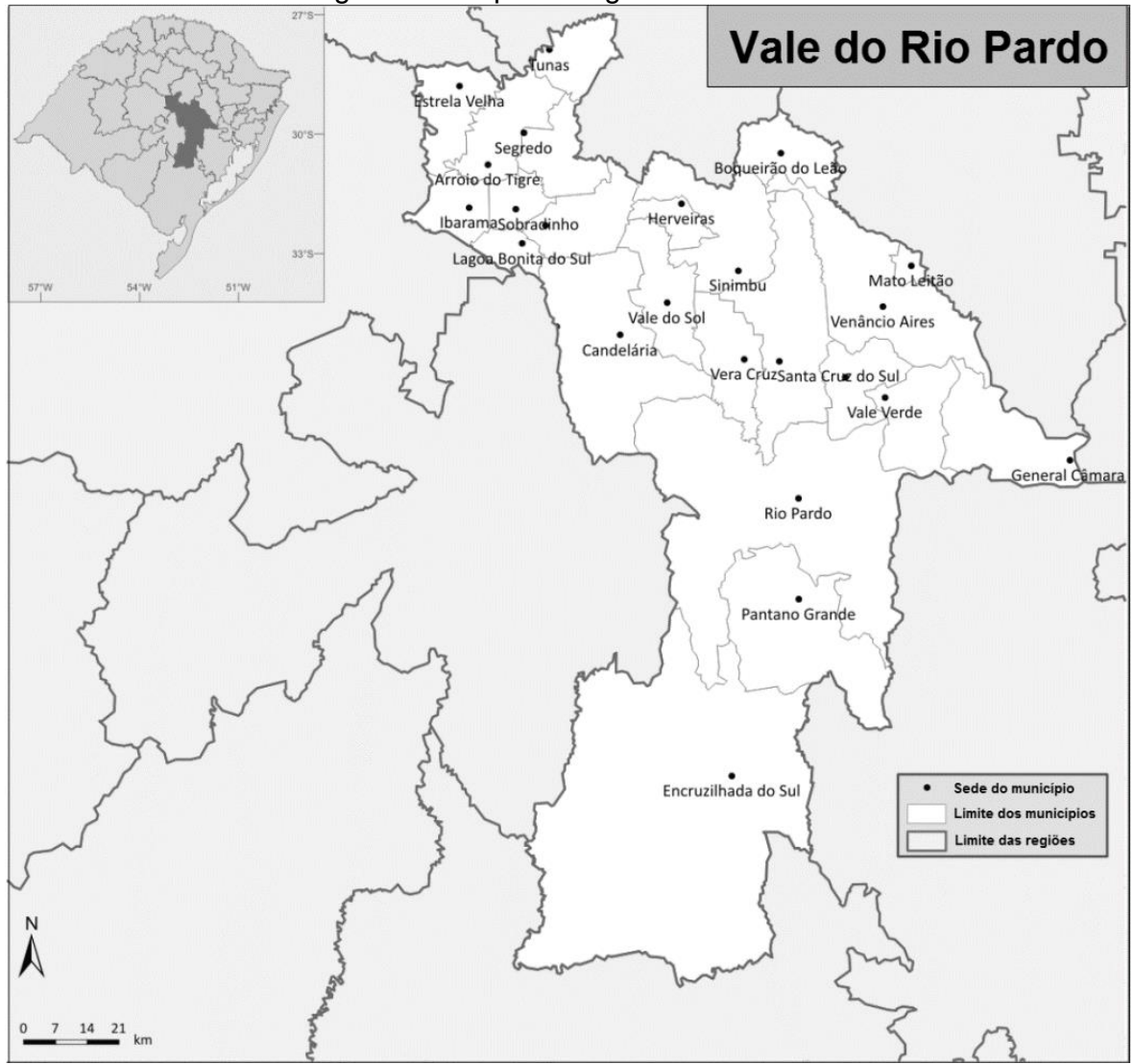

Fonte: FEE (2015) 
Conforme levantamento do IRGA (2016) há produção de arroz em 11 dos 23 municípios da região, totalizando 32.065 hectares semeados na safra de 2015/2016. Candelária, Rio Pardo e Pantano Grande são os que detêm as maiores áreas com, respectivamente, $8.950,8.158$ e 4.175 , representando $66 \%$ do total da área regional cultivada com o cereal. A Região do Vale do Rio Pardo foi responsável pela produção de 187 mil toneladas nos 29.420 hectares colhidos na safra 2015/2016, obtendo uma produtividade média de 6.385 quilogramas por hectare (TABELA 04), 8\% a menos que a média estadual registrada nessa mesma safra, que foi de 6.928 quilogramas por hectare (TABELA 04).

Tabela 4 - Área $(\mathrm{Ha})$, produção $(\mathrm{Kg})$ e produtividade $(\mathrm{Kg} / \mathrm{ha})$ dos municípios da Região do Vale do Rio Pardo, Safra 2015/2016

\begin{tabular}{cccccc}
\hline Município & $\begin{array}{c}\text { Área } \\
\text { Semeada }\end{array}$ & $\begin{array}{c}\text { Área } \\
\text { Perdida }\end{array}$ & $\begin{array}{c}\text { Área } \\
\text { Colhida }\end{array}$ & $\begin{array}{c}\text { Produtivi } \\
\text { dade }\end{array}$ & Produção \\
\hline Candelária & 8.950 & 221 & 8.729 & 6.746 & 58.885 .834 \\
\hline $\begin{array}{c}\text { Encruzilhada do Sul } \\
\text { (norte) }\end{array}$ & 100 & 0 & 100 & 6.350 & 635.000 \\
\hline $\begin{array}{c}\text { Encruzilhada do Sul } \\
\text { (sul) }\end{array}$ & 1.308 & 17 & 1.291 & 7.535 & 9.727 .685 \\
\hline General Câmara & 1.859 & 65 & 1.794 & 5.495 & 9.858 .030 \\
\hline Pantano Grande & 4.175 & 695 & 3.480 & 7.065 & 24.586 .200 \\
\hline Passo do Sobrado & 690 & 0 & 690 & 6.011 & 4.147 .590 \\
\hline Rio Pardo & 8.158 & 1.203 & 6.955 & 5.766 & 40.102 .530 \\
\hline Santa Cruz do Sul & 1.700 & 78 & 1.622 & 6.478 & 10.507 .316 \\
\hline Vale do Sol & 1.050 & 20 & 1.030 & 6.783 & 6.986 .490 \\
\hline Vale Verde & 1.175 & 105 & 1.070 & 5.779 & 6.183 .530 \\
\hline Venâncio Aires & 1.900 & 139 & 1.761 & 6.152 & 10.833 .672 \\
\hline Vera Cruz & 1.000 & 102 & 898 & 6.014 & 5.400 .572 \\
\hline TOTAL & $\mathbf{3 2 . 0 6 5}$ & $\mathbf{2 . 6 4 5}$ & $\mathbf{2 9 . 4 2 0}$ & $\mathbf{6 . 3 8 5}$ & $\mathbf{1 8 7 . 8 5 4 . 4}$ \\
\hline
\end{tabular}

Fonte: IRGA, 2016

Para uma maior aproximação com a realidade orizícola da Região do Vale do Rio Pardo e caracterização de seus produtores, serão aqui utilizados dados do Minicenso realizado pelo Instituto Rio Grandense do Arroz na safra 2014-2015, trazendo informações dos municípios de Candelária, Rio Pardo e Pantano Grande os três municípios apresentam a maior produção de arroz do Vale do Rio Pardo, , com respectivamente 8700,8500 e 4600 hectares, que somavam naquela safra uma área de 22.536 hectares e são responsáveis por $67,5 \%$ das 250 mil toneladas de arroz produzidas na Região (IRGA, 2018).

Uma característica da lavoura arrozeira, que se perpetua ao longo da história, é o arrendamento de terras de grandes fazendas por produtores rurais, principalmente mais ao sul do VRP, onde prevalecem descendentes açorianos. Conforme a Tabela 05, Rio Pardo e Pantano Grande têm, respectivamente, $79 \%$ e $60 \%$ de seu cultivo em áreas arrendadas; já o município de Candelária, com predomínio de descendentes alemães, apresenta $45 \%$ das áreas arrendadas.

Outro ponto que se pode destacar nesta tabela é o percentual da área cultivada em rotação com culturas de soja, milho e pastagem, valor este que indica 
uma conscientização dos produtores sobre a necessidade de reconversão de áreas infestadas por arroz vermelho ${ }^{3}$ para uma produção sustentável, além de ser uma diversificação na renda da propriedade. Vale ressaltar, porém, que nem todas as áreas podem ser utilizadas com outros cultivos. O município de Candelária, com 19\% da área com rotação de culturas, é caracterizado por áreas menores, planas, baixas e de difícil drenagem, dificultando a expansão de outras culturas. Rio Pardo, com $26 \%$ da área em rotação, possui áreas intermediárias, possibilitando outros cultivos. Já em Pantano Grande, que possui $60 \%$ da lavoura cultivada em rotação com outras culturas, predominam grandes extensões de áreas, com relevo menos plano e com menor probabilidade de inundações, facilitando a inserção de outras culturas nessas áreas de várzea.

Tabela 5 - Área total cultivada, área arrendada, e área cultivada com rotação de culturas (soja, milho e/ou pastagens) dos Municípios de Candelária, Pantano Grande e Rio Pardo na Safra 2014/2015

\begin{tabular}{|c|c|c|c|c|c|c|c|}
\hline & $\begin{array}{l}\text { Área total } \\
\text { (ha) }\end{array}$ & $\begin{array}{l}\text { Arrendada } \\
\text { (ha) }\end{array}$ & $\begin{array}{c}\text { Arrendada } \\
(\%)\end{array}$ & $\begin{array}{l}\text { Própria } \\
\text { (ha) }\end{array}$ & $\begin{array}{l}\text { Própria } \\
(\%)\end{array}$ & $\begin{array}{l}\text { Rotação } \\
\text { (ha) }\end{array}$ & $\begin{array}{c}\text { Rotação } \\
(\%)\end{array}$ \\
\hline Candelária & 8950 & 4027 & $45 \%$ & 4923 & $55 \%$ & 1709 & $19 \%$ \\
\hline $\begin{array}{l}\text { Pantano } \\
\text { Grande }\end{array}$ & 4337 & 2620 & $60 \%$ & 1717 & $40 \%$ & 2810 & $65 \%$ \\
\hline Rio Pardo & 9249 & 7344 & $79 \%$ & 1905 & $21 \%$ & 2366 & $26 \%$ \\
\hline Total & 22536 & 13991 & $62 \%$ & 8545 & $38 \%$ & 6885 & $31 \%$ \\
\hline
\end{tabular}

Fonte: Elaborado pelo autor com base em dados do Irga (2015).

A Tabela 05 evidencia essas diferenças entre os municípios do VRP. No município de Candelária $75 \%$ dos produtores, 216 do total de 288 , cultivam uma área menor que 50 hectares, representando $30 \%$ do total da área de arroz do município. Não existe ali nenhum produtor com área maior que 201 hectares. Para Rio Pardo, o número de produtores com área de até 50 hectares é de 47 , quase $50 \%$, porém já aparece um número maior de produtores com áreas superiores a 101 hectares. Já em Pantano Grande, essa realidade é bem diferente, $83 \%$ dos produtores possuem área superior a 51 hectares, e $53 \%$ dos 4337 hectares de arroz do município são cultivados por apenas 9 produtores, que cultivam áreas superiores a 201 hectares.

\footnotetext{
${ }^{3} \mathrm{O}$ arroz-vermelho (Oryza sativa L.) é a principal planta daninha em lavouras de arroz. Possui características genéticas, morfológias e bioquímicas semelhantes ao arroz cultivado, sendo, assim, de difícil controle. E é responsável por significativas reduções de produtividade e qualidade de grãos de arroz (SOSBAI, 2018).
} 
Tabela 6 - Número de produtores e percentual da área cultivada, estratificados pelos tamanhos das lavouras

\begin{tabular}{|c|c|c|c|c|c|c|c|c|c|}
\hline \multirow{2}{*}{ Município } & \multirow{2}{*}{$\begin{array}{l}\text { Número de } \\
\text { produtores }\end{array}$} & \multicolumn{2}{|c|}{ Até 50 ha } & \multicolumn{2}{|c|}{$\begin{array}{c}\text { De } 51 \text { a } 100 \\
\text { ha }\end{array}$} & \multicolumn{2}{|c|}{$\begin{array}{c}\text { De } 101 \text { a } 200 \\
\text { ha }\end{array}$} & \multicolumn{2}{|c|}{$\begin{array}{l}\text { Acima de } \\
201 \text { ha }\end{array}$} \\
\hline & & $\begin{array}{c}\text { NN.o } \\
\text { Prod. }\end{array}$ & $\%$ & $\begin{array}{c}\text { NN.o } \\
\text { Prod. }\end{array}$ & $\%$ & $\begin{array}{l}\text { NN.o- } \\
\text { Prod. }\end{array}$ & $\%$ & $\begin{array}{l}\text { NN.o } \\
\text { Prod. }\end{array}$ & $\%$ \\
\hline Candelária & 288 & 216 & 30,3 & 43 & 28,9 & 29 & 40,8 & 0 & 0 \\
\hline $\begin{array}{c}\text { Pantano } \\
\text { Grande }\end{array}$ & 30 & 5 & 3,6 & 8 & 16,5 & 8 & 26,9 & 9 & 53 \\
\hline Rio Pardo & 98 & 47 & 15,1 & 19 & 16,8 & 20 & 30,7 & 12 & 37,4 \\
\hline Total & 416 & 268 & 18,9 & 70 & 21,5 & 57 & 34,0 & 21 & 25,5 \\
\hline
\end{tabular}

Fonte: Elaborado pelo autor com base em dados do Irga (2015).

Um fator de grande importância para a sustentabilidade dos produtores de arroz é a sua produtividade. Com a Tabela 06 pode-se visualizar a distribuição dos produtores de acordo com sua produtividade. Não há uma relação direta entre o tamanho da área do produtor e sua produtividade; tem-se pequenos e grandes produtores de arroz com altas e baixas produtividades.

Tabela 7 - Número de produtores e percentual da área cultivada por faixa de produtividade média

\begin{tabular}{|c|c|c|c|c|c|c|c|c|}
\hline \multirow[b]{2}{*}{ Município } & \multicolumn{2}{|c|}{$\begin{array}{c}\text { Até } 6500 \\
\mathrm{~kg} / \mathrm{ha}\end{array}$} & \multicolumn{2}{|c|}{$\begin{array}{c}\text { De } 6501 \text { a } 7500 \\
\text { kg/há }\end{array}$} & \multicolumn{2}{|c|}{$\begin{array}{c}\text { De } 7501 \text { a } 8500 \\
\mathrm{~kg} / \mathrm{ha}\end{array}$} & \multicolumn{2}{|c|}{$\begin{array}{c}\text { Acima de } 8501 \\
\mathrm{~kg} / \mathrm{ha}\end{array}$} \\
\hline & $\begin{array}{l}\text { N.ㅇ } \\
\text { Prod. }\end{array}$ & $\%$ & NN. Prod. & $\%$ & $\begin{array}{c}\text { NN.o } \\
\text { Prod. }\end{array}$ & $\%$ & $\begin{array}{c}\text { N.o } \\
\text { Prod. }\end{array}$ & $\%$ \\
\hline Candelária & 9 & 2,34 & 187 & 60,24 & 83 & 35,02 & 9 & 2,4 \\
\hline $\begin{array}{l}\text { Pantano } \\
\text { Grande }\end{array}$ & 4 & 9,8 & 8 & 29,5 & 8 & 19,6 & 10 & 41,1 \\
\hline Rio Pardo & 22 & 27,9 & 36 & 32,4 & 26 & 27,8 & 14 & 11,9 \\
\hline Total & 35 & 14,3 & 231 & 42,9 & 117 & 29,1 & 33 & 13,7 \\
\hline
\end{tabular}

Fonte: Elaborado pelo autor com base em dados do Irga (2015).

Um dado a ressaltar é o percentual de orizicultores da região com produtividades inferiores à média do estado - de $7780 \mathrm{~kg} / \mathrm{ha}$ na safra 2014/2015. Em Candelária e Rio Pardo, $68 \%$ e $59 \%$ dos produtores, respectivamente, colheram menos que $7.500 \mathrm{~kg} / \mathrm{ha}$; em Pantano Grande são $40 \%$ dos produtores nessa faixa de produtividade. Não cabe aqui entrar no mérito nem aprofundar sobre o motivo desses produtores terem essas baixas produtividades, porém, é um dado importante a ser considerado em estudos sobre o desenvolvimento e a subsistência da cadeira orizícola na Região. 
Figura 3 - Mapa da produção de arroz na Região do Vale do Rio Pardo

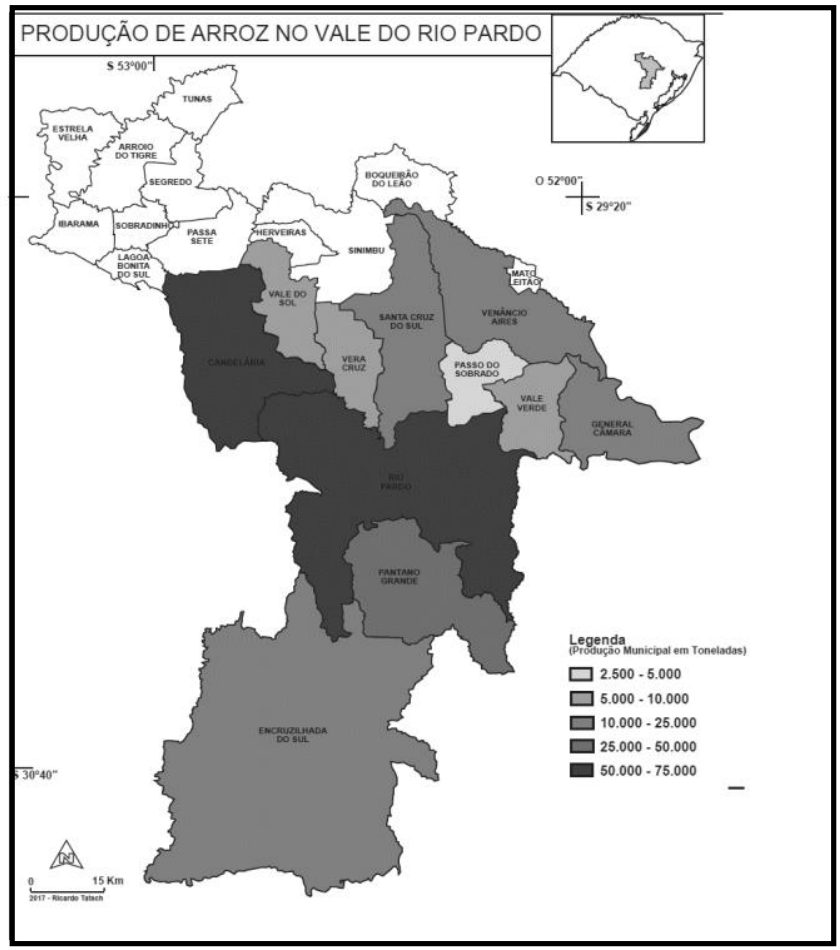

Fonte: Elaborado pelo autor com base em dados do IRGA (2017).

Os dados até aqui levantados falam da importância histórica que o arroz tem para o Rio Grande do Sul e das características desse cultivo no Vale do Rio Pardo, com destaque para três cidades investigadas nesse estudo - Candelária, Pantano Grande e Rio Pardo. Esses dados são importantes porque ajudam a contextualizar o ambiente vivido pelos produtores rurais e influenciam na forma como esses percebem a realidade que os cerca.

$\mathrm{Na}$ próxima seção será discutida a temática da gestão rural nas propriedades, sua importância e desafios de implementação.

\section{PERFIL E A GESTÃO RURAL DOS ORIZICULTORES DO MUNICÍPIO DE RIO PARDO-RS}

Nesta seção serão apresentados os procedimentos metodológicos, o perfil dos produtores de arroz do município de Rio Pardo e as questões relacionadas com a importância da compreensão do processo de gestão nas propriedades rurais.

\subsection{CAMINHO METODOLÓGICO}

A pesquisa caracteriza-se por exploratória (GIL, 1999), buscando ampliar os conhecimentos sobre o perfil dos orizicultores e a forma como eles têm utilizado - ou não - técnicas gerenciais que possibilitem o controle e a sustentabilidade do seu 
negócio. Além disso, conforme destacado na introdução, foi realizada revisão bibliográfica e foram mobilizados dados secundários - CONAB (2018); FEE (2015); IBGE (2017); IRGA (20006); USDA/FAZ (2018); (IRGA, 2018) que auxiliam na compreensão das informações levantadas.

Para construção do perfil e análise da utilização dos controles econômicosfinanceiros, as informações foram colhidas, através de um questionário semiestruturado realizado, por telefone com 37 dos 63 produtores do município de Rio Pardo-RS. Foram exploradas sete questões fechadas e uma abordando a forma como se dá a produção do arroz e algumas características dos orizicultores. Primeiro, foi analisada a área e a produtividade dessa. Depois, o número de pessoas - familiares ou empregados - envolvidos na produção; o tempo de experiência do agricultor nessa forma de cultivo; seu grau de escolaridade. Em um segundo momento, buscou-se saber se esse produtor possui acesso a informações online, se faz uso de recursos próprios ou de terceiros, se possui um controle de custos e, como pergunta aberta, se Ihe é conhecida a rentabilidade do seu negócio.

Como método de análise das informações optou-se pela análise de conteúdo. Essa consiste em três fases: 1) pré-análise: organização do material de acordo com os objetivos e questões, definindo as unidades de registro e de contexto, destacando as partes mais significativas e criando categorias; 2) análise: aplicação da anterior, momento de múltiplas leituras do material; 3) tratamento dos resultados e interpretação: desvendar o conteúdo subjacente das mensagens, buscar por tendências, ideologias, etc. (GOMES, 2002). Tal análise, baseou-se em quatro categorias analíticas: controles gerenciais, gestão rural, agricultura familiar, produtores de arroz. Buscou-se analisar as relações dos produtores com as técnicas de gestão, posto que se acredita, como Callado et al. (2007) e Crepaldi (2006) que a contabilidade e as técnicas de gestão são recursos que auxiliam na tomada de decisão dos produtores rurais. Podem auxiliar nos processos administrativos e produtivos, facilitando escolhas, possibilitando obter rendimentos adicionais, diluir custos e economizar insumos. Analisar as 37 entrevistas realizadas, além das contribuições trazidas pelo cruzamento dos dados das questões fechadas. Na seção 3.2 são apresentados esses dados que definem o perfil dos orizicultores entrevistados e trazem algumas informações sobre as áreas cultivadas por esses.

\subsection{PERFIL DOS ORIZICULTORES DO MUNICÍPIO DE RIO PARDO-RS}

A partir da coleta de dados, através de questionários aplicados, junto aos produtores de arroz do município de Rio Pardo - RS, foi possível fazer uma caracterização da produção orizícola do município, identificando-se características relacionadas à estrutura e a gestão das propriedades.

Quanto ao domínio da área, os arrozeiros podem ser proprietários da terra, arrendatários, ou cultivar em terras mistas (próprias ou arrendadas). Em 2006, 60\% da área sob o cultivo de arroz no Rio Grande do Sul era arrendada e, para Rio Pardo, esse índice era de 75\% (IRGA, 2006). Questionando os produtores selecionados nesse estudo, chegou-se a um índice ainda maior para o município: $79 \%$ das áreas de arroz de Rio Pardo são arrendadas. No que se refere à produtividade, foi apurado entre os produtores do município uma média de 7.564 quilogramas por hectare, apenas $2 \%$ abaixo dos 7.725 quilogramas estimados para o Estado na safra 2016/2017 (TABELA 3). O arrendamento de terras é uma realidade da orizicultura gaúcha que se perpetua ao longo da história. No município de Rio Pardo, $79 \%$ das áreas de produção de arroz são arrendadas; $60 \%$ em Pantano Grande; e 45\% em Candelária (IRGA, 2015). Essa prática representa um grande valor no custo de produção, em média 25 sacas de arroz ( $R \$ 915,39)$ por hectare (IRGA, 2018). 
Portanto, há uma vantagem financeira para quem é proprietário e não precisa arcar com esse valor.

O tempo de experiência dos rio-pardenses no cultivo de arroz é alto, 31 dos 37 entrevistados estão há mais de 30 anos na atividade, 4 deles têm entre 20 e 30 anos de cultivo e os outros 2 possuem de 10 a 20 anos. Logo, existe uma tradição na produção local de arroz. Questionados também a respeito da mão de obra utilizada, $58 \%$ é familiar, $23 \%$ composta por funcionários permanentes e $19 \%$ de temporários. Evidenciando o prevalecimento da mão de obra familiar para o desenvolvimento das atividades e condução dos negócios. Quanto ao tamanho das propriedade, elas variam entre pequena, grande e média, com diferentes fontes de acesso às informações e diferentes formas de tomarem as decisões no que se refere ao bom andamento de seus negócios.

A escolaridade variou entre o quarto ano do ensino fundamental e a pósgraduação, mostrando também aqui uma diversidade no desenvolvimento do conhecimento formal. Como identificado anteriormente, as mais baixas escolaridades estão relacionadas às mais altas idades, certamente porque haviam maiores dificuldades de acesso às escolas quando esses se encontravam em idade escolar, além de uma baixa valorização do conhecimento formal e da necessidade do envolvimento das crianças no trabalho familiar.

Para se manterem no negócio esses produtores vêm, de alguma maneira, driblando com a questão da rentabilidade, buscando reduzir os custos de produção. Seja melhorando o resultado da operação, desde que não reduza também a produtividade ou buscando a diversificação de atividades, possibilitando um complemento da renda das propriedades. No entanto, a atividade orizícola continua sendo a responsável pelo maior percentual do faturamento bruto da propriedade.

Além das diferenças no perfil desses produtores, é possível notar que as formas de reação em momentos de crise também têm grande variação. Observam-se situações em que produtores que estavam muito bem financeiramente e, no primeiro contratempo, não conseguiram se "reerguer". Sua alternativa para o enfrentamento da crise foi, portanto, redução da área, da tecnologia e do espaço destinado ao cultivo de arroz, hoje dividido com a produção de soja. Esses dados sobre o enfrentamento de crises mostram as diferentes formas pelas quais os produtores rurais agem e reagem frente a influências externas. Um fator que precisa ser considerado, ainda, quando se pensa na heterogeneidade nas formas de ação dos produtores é a sua capacidade para arcar com essas perdas. Afinal, sua capacidade de agência não é independente de questões estruturais (GIDDENS, 2003; LONG; PLOEG, 2011) e, como visto, muitos precisam abrir mão de seu patrimônio para superar esses momentos. Para isso, é preciso que possuam esses recursos a serem acionados em momentos de crise. O mais essencial desses recursos, para o produtor, é a terra.

No que se trata das formas de gerenciamento agrícola, trata das experiências, critérios e valores envolvidos no processo de tomada de decisão que criam uma gama de resultados diferenciados (BESSEN, 2016). Portanto, acredita-se que as diferentes experiências vivenciadas pelos produtores rurais influenciam a forma como esses vivenciam o seu cotidiano e como agem e reagem frente às transformações - como a queda na lucratividade e a necessidade de um maior controle contábil nas propriedades. Para resolver esses problemas e enfrentar crises, muitas são as respostas possíveis.

Portanto, situações semelhantes ou diferentes podem ser modificadas pela ação dos atores. Ainda que as condições econômicas possam ser pouco vantajosas, elas restringem, mas não impedem o poder de ação. $O$ oposto também se verifica: situações em que os produtores encontram facilidades econômicas podem ser negativamente influenciadas pela ação (ou inação) desses. 
Resumidamente, pode-se destacar que os orizicultores do município de Rio Pardo, de modo geral, arrendam terras para o cultivo do arroz, que a maior parte deles está a mais de 30 anos na atividade, que o tamanho das propriedades é variado e que a maioria apresenta ensino fundamental incompleto. No próximo item analisa-se a gestão das propriedades orizícolas no município de Rio Pardo-RS.

\subsection{GESTÃO RURAL NAS PROPROEDADES ORIZÍCOLAS NO MUNICÍPIO DE RIO PARDO-RS}

$\mathrm{Na}$ segunda parte do questionário foram tratadas questões relativas aos controles de custos utilizados pelos produtores rurais no desenvolvimento de suas atividades. Pode-se observar que apenas 16 produtores dos 37 entrevistados possuem algum tipo de anotação ou controle e nenhum se utiliza de ferramentas mais sofisticadas, como programas ou planilhas digitais. Os demais (21 produtores) sequer possuem anotações de custos da lavoura.

Buscou-se apurar o custo da lavoura. No entanto, somente um produtor rural respondeu afirmativamente. Isso demonstra a precariedade com que são realizados o controle de custos e a gestão das propriedades. Surpreende ainda a averiguação de que o produtor que possui a contabilidade mais efetiva concluiu apenas o Ensino Fundamental. Isso mostra que o baixo grau de escolaridade não é, necessariamente, um impedimento para a utilização de instrumentos contábeis para o controle da atividade.

Para avaliar a questão da busca por conhecimento sobre a gestão rural, focando na iniciativa do produtor em encontrar informações em meios formais ou informais. Vale ressaltar que essa busca é influenciada por muitos fatores sociais, econômicos, políticos e morais. Long e Ploeg (2011) enfatizam ainda que os atores agem em seu cotidiano porque estão sempre buscando alternativas e aprendendo com os atores ao seu redor. Essas respostas são importantes porque mostram que apesar de não possuírem um conhecimento formal sobre a gestão, de alguma forma esses atores exercem a agência nesse quesito, posto que tomam as decisões que afetam o seu cotidiano (GIDDENS, 2003). Apesar disso, essas decisões não têm levado os produtores a uma melhoria na saúde financeira de suas propriedades ou à sua satisfação no campo.

No entanto, o uso de TICs pode facilitar a previsão do tempo de plantio, informar com maior eficiência os valores de produtos e insumos e influenciar positivamente o andamento de uma propriedade. Considera-se aqui, portanto, que o envolvimento direto no cotidiano braçal do trabalho no meio rural é um limitador da agência no quesito gestão, fazendo com que outros fatores - como a produtividade tornem-se mais importantes. Não se afirma, com isso, que a produtividade ou a gestão tenham importâncias inferiores ou superiores uma à outra, apenas que os produtores não consideram, em termos gerais, a importância da gestão rural.

Como visto, a capacidade dos agentes no quesito gestão aparece influenciada por inúmeros fatores - a idade, o acesso às TICs, a escolaridade, às disponibilidades institucionais (como cursos disponibilizados), o grau de envolvimento no trabalho braçal e também à busca dos atores por maiores informações na área.

Para compreender esses processos na realidade estudada, é preciso compreender as dificuldades que os produtores têm em se manterem em atividade, dado o alto custo de produção e a queda no preço das vendas do arroz. As formas de gestão e de consciência sobre a necessidade de tomar decisões com embasamento são parte da resistência dos orizicultores para darem continuidade às suas atividades no meio rural. Assim, "Os recursos dos agricultores concentram-se nas suas decisões, na forma de gestão do estabelecimento rural, nas redes formadas, nas suas 
organizações, nas diferentes maneiras de responder aos problemas" (DEPONTI; ALMEIDA, 2012, p. 212).

Deponti (2014), ao analisar a gestão nas propriedades rurais, identificou que mesmo tendo acesso às tecnologias da informação, não há uma consciência de que essas possam ser utilizadas no registro das informações e do controle de despesas para embasar a tomada de decisão. Brandão (2011) e Fontoura e Wittimann (2016) identificaram que a gestão pode ser uma forma de empoderar os agricultores, ampliando seu olhar sobre as atividades agrícolas, incentivando o desenvolvimento de organizações rurais. (BRANDÃO, 2011; FONTOURA; WITTIMANN, 2016). A autonomia do produtor, seja essa financeira ou gerencial é de fundamental importância para sua sustentabilidade no meio rural.

\section{CONSIDERAÇÕES FINAIS}

Ao longo deste artigo fez-se uma caracterização do cultivo de arroz em níveis nacional, estadual, regional e municipal, demonstrando a importância deste cereal para a região. E, com a aplicação de questionário, se caracterizou e definiu o perfil dos orizicultores do município de Rio Pardo, segundo maior produtor de arroz do Vale do Rio Pardo, quanto à estrutura e à gestão de suas propriedades.

Concluiu-se que o conhecimento do perfil dos produtores poderá servir de instrumento de auxílio no desenvolvimento de programas relacionados à contabilidade rural. Os dados levantados justificam a necessidade de estudos que busquem conhecer a realidade de gerenciamento das propriedades dos agricultores, tendo em vista que se tem dado pouca ênfase à capacitação gerencial destes produtores. Outra questão relevante seria a busca de alternativas para melhorar, ou mesmo implantar, uma gestão rural adequada à realidade da agricultura.

Sobre a questão específica da gestão, percebeu-se que a maioria declara não fazer por falta de conhecimento e de tempo, mas percebem a necessidade de aprimoramento dessa questão em suas propriedades. Isso vem mostrar que existe uma abertura para o aprimoramento dos produtores nessa área, mas qualquer forma de intervenção deve ser direcionada para a multiplicidade de públicos ali presentes, considerando suas diferentes capacidades e interesses.

Portanto, considera-se que essa pesquisa, além de tratar de uma importante questão - a gestão do negócio dos produtores na orizicultura -, pode também contribuir para futuras intervenções de extensão rural. Isso porque mostra que é necessário vislumbrar e tentar compreender o outro lado - a percepção dos orizicultores sobre sua realidade. É ainda essencial trazer à tona a diversidade existente nesta produção, quer seja ela relacionada a utilização de técnicas de contabilidade e gestão, ou a outros fatores que influenciam na forma como esses atores compreendem e interagem no universo que os circunda.

A utilização de ferramentas de contabilidade e técnicas de gestão ainda é uma realidade distante para um grande número de propriedades. Isso mostra a não adoção de técnicas formais básicas de contabilidade. A preocupação e a utilização da contabilidade, pelos produtores, dá-se essencialmente para fins de cálculo do imposto de renda, não sendo utilizada para a melhoria da gestão do seu negócio.

Um fator que se mostrou de fundamental importância, mas que acaba passando desapercebido por grande parte dos orizicultores é o tempo. Tempo para se dedicar à contabilidade e à gestão da propriedade; tempo para olhar o seu negócio com distanciamento; tempo para acompanhar o mercado e fazer negócios melhores. Portanto, avalia-se que o envolvimento direto no trabalho cotidiano é um limitador da agência no quesito gestão, fazendo com que outros fatores - como a produtividade tornem-se mais importantes. Porém, para que se consiga uma boa produtividade, e 
que esta gere rentabilidade e satisfação para o produtor rural, acredita-se que é necessário que a produção e as técnicas de gestão andem em sintonia.

A capacidade dos agentes no quesito gestão aparece influenciada por inúmeros fatores, dentre eles a heterogeneidade no meio rural. Como foi visto, são inúmeras as diferenças, mesmo entre essa pequena amostra de orizicultores, que influenciam as vivências desses no campo. Não se pode ignorar esse fator, posto que isso implicaria em generalizações que podem ser prejudiciais para pensar em soluções para os problemas no meio rural. Nesse contexto se compreende, portanto, que a heterogeneidade se caracteriza nas variadas formas com que os produtores vivenciam as suas realidades e reagem às influências externas.

Há uma grande variação na idade, tempo de experiência, escolaridade, tamanho da área de produção, posse da área, origem do custeio da lavoura, saúde financeira e satisfação no meio rural dentre os produtores investigados. Além das diferenças no perfil desses produtores, é possível notar que as formas de reação em momentos de crise também têm grande variação. Observou-se produtores que estavam bem financeiramente e que, no primeiro contratempo, não conseguiram mais se reerguer. Mesmo vendendo o pouco que ainda possuem, não é suficiente para quitar as dívidas. Outras situações mostram produtores que estavam financeiramente devastados depois de sofrerem crises - seja por contratempos climáticos ou maus investimentos, mas conseguiram se recuperar. Desfizeram-se de patrimônio, reduziram custos desnecessários, adequaram tamanho da área à capacidade produtiva ou investiram em tecnologia e, assim, conseguiram não só quitar as dívidas, mas também adquirir terras e fazer novos investimentos na estrutura produtiva de suas propriedades.

Entretanto, como foi afirmado, não se pode implementar ferramentas de contabilidade e gestão no meio rural na forma de um pacote tecnológico. É preciso considerar que esses atores são agentes reflexivos que não vão absorver de forma igualitária esses conhecimentos. Possivelmente essa forma de extensão falharia para um grande número de produtores. É preciso considerar sua diversidade; suas diferentes capacidades e formas de ação; e os vastos conhecimentos que eles já trazem consigo. O fator chave é entender a percepção do produtor sobre a necessidade desse conhecimento para o sucesso do seu negócio. A partir dessa pesquisa foi possível elucidar como os orizicultores desenvolvem seus saberes, lutam por autonomia, diferenciam-se uns dos outros e agem para transformar a realidade em que vivem. Expressa-se o desejo de que ele possa servir de subsídio para outros que se interessem em compreender como se dá o processo de gestão no meio rural a partir da visão dos agricultores.

\section{REFERÊNCIAS}

BARATA, T. S. Caracterização do consumo de arroz no Brasil: um estudo na Região Metropolitana de Porto Alegre. Dissertação (Mestrado). Porto Alegre: UFRGS/Cepan. 2005.

BATALHA, M. O.; SCARPELLI, M. Gestão da cadeia agroindustrial. In: WORKSHOP: O AGRONEGÓCIO NA SOCIEDADE DA INFORMAÇÃO, Anais... Brasília, DF: Programa Sociedade da Informação - MCT, Brasília 2002.

BESSEN, F. G. Políticas públicas para a agricultura familiar no município de Entre Rios do Oeste: uma análise a partir da teoria ator orientado. Dissertação (Programa de Pós-Graduação em Desenvolvimento Rural Sustentável do Centro de 
ciências Agrárias da Unioeste - Universidade do Oeste do Paraná), 124 p. Marechal Cândido Rondon, Paraná, 2016.

BORILLI, S. P. et al. O uso da contabilidade rural como uma ferramenta gerencial: um estudo de caso dos produtores rurais no município de Toledo. Rev. Ciências Empresariais da UNIPAR, Toledo, v.6, n.1 p. 77-95, jan./jun, 2005.

BRANDÃO, C. Estratégias hegemônicas e estruturas territoriais: o prisma analítico das escalas espaciais. Bahia Análise \& Dados, Salvador, v. 21, n. 2, p. 303-313, abr./jun. 2011.

BRASIL Ministério da Agricultura, Pecuária e Abastecimento (MAPA) Projeções do Agronegócio - Brasil 2015/16 a 2025/26. Brasília, 2016. Disponível em: http://www.agricultura.gov.br/assuntos/politica-agricola/todas-publicacoes-de-politicaagricola/projecoes-do-

agronegocio/proj_agronegocio2016.pdf/@@download/file/Proj_Agronegocio2016.pdf . Acesso em: 12 dez. 2020.

CALLADO, A. L. C. Custos no processo de tomada de decisão em

empresas rurais. 2007. Disponível em: http://www.sebrae.gov.br/bibliotecaonline. Acesso em: 12 dez. 2017.

COMPANHIA NACIONAL DE ABASTECIMENTO, CONAB. A cultura do arroz. Brasil, 2015.2 Disponível em: http://www.conab.gov.br/OlalaCMS/uploads/arquivos/16_03_01_16_56_00_a_cultur a_do_arroz_-_conab.pdf. Acesso em: 12 dez. 2020.

COMPANHIA NACIONAL DE ABASTECIMENTO, CONAB. Custo da Produção de Arroz. 2016. Disponível em: http://www.conab.gov.br/. Acesso em: 12 dez. 2020.

CREPALDI, S. A. Contabilidade rural: uma abordagem decisorial. São Paulo:Atlas, 1998.

CREPALDI, S. A. Contabilidade rural: uma abordagem decisorial. 4 ed. São Paulo: Atlas, 2006.

CREPALDI, S. A. Contabilidade Rural. São Paulo: Atlas, 2009.

DEPONTI, C. M. As agruras da gestão da propriedade rural pela Agricultura Familiar. Rev. Des. Regional, Santa Cruz do Sul, v. 19, ed. especial, p. 9-24, 2014.

DEPONTI, C. M.; ALMEIDA, J. P. Dinâmicas de interface social e intervenção pública: - caso da extensão rural do Rio Grande do Sul. Redes - Revista de desenvolvimento regional, Santa Cruz do Sul, RS, v. 17, n. 2, p. 195-214, maio/ago. 2012.

GIDDENS, A. A constituição da sociedade. 2.ed. São Paulo: Martins Fontes, 2003.

GIL, A. C. Métodos e técnicas de pesquisa social. São Paulo: Atlas, 2009.

GOMES, R. A análise de dados em pesquisa qualitativa. In: MINAYO, M. C. S. (Org.). Pesquisa social: teoria, método e criatividade. Petrópolis: Vozes, 2002. p. 67-80. 
FEE - Fundação de Economia e Estatística. Perfil Sócio Econômico COREDE Vale do Rio Pardo. Porto Alegre, 2015. Disponível em: http://www.fee.rs.gov.br/perfilsocioeconomico/coredes/detalhe/?corede=Vale+do+Rio+Pardo. Acesso em: $12 \mathrm{dez}$. 2020.

FONTOURA, F. B. B.; WITTMANN, M. L. Organizações e Desenvolvimento: reflexões epistemológicas. Estudos do CEPE, v. 43, p. 30, 2016.

GIL, A. C. Métodos e técnicas de pesquisa social. 5 ed. São Paulo: Atlas, 1999.

IBGE - Instituto Brasileiro de Geografia e Estatística. Censo Agropecuário 2017. Disponível em: https://www.ibge.gov.br/estatisticasnovoportal/economicas/agricultura-e-pecuaria/21814-2017-censoagropecuario.html?=\&t=resultados. Brasília, 2018. Acesso em: 21 out. 2020.

IRGA - Instituto Rio Grandense do Arroz. Censo da Lavoura de Arroz Irrigado do Rio Grande do Sul - Safra 2004/2005. Porto Alegre, 2006. Disponível em: http://www3.irga.rs.gov.br/uploads/anexos/1292592973censodg3.pdf. Acesso em: 12 dez. 2020.

IRGA - Instituto Rio Grandense do Arroz. Produção municipal. 2016. Disponível em: http://www.irga.rs.gov.br/conteudo/6911/safras. Acesso em abril/2021.

LONG, N.; PLOEG, J. D. Heterogeneidade, ator e estrutura: para a reconstituição do conceito de estrutura. In: SCHEIDER, S; GAZOLLA, M. (Orgs.). Os atores do desenvolvimento rural - perspectivas teóricas e práticas sociais. Porto Alegre: Editora da UFRGS, 2011. p. 21-48.

PEREIRA, J. A. Cultura do arroz no Brasil: subsídios para a sua história. Teresina: Embrapa Meio-Norte, 2002.

PELEGRINI, G.; GAZOLLA, M. A. Agroindústria familiar no Rio Grande do Sul: limites e potencialidades da sua reprodução social. Frederico Westphalen: Uri, 2008.

SOSBAI - Sociedade Sul Brasileira de Arroz Irrigado. Arroz irrigado: recomendações técnicas para o sul do Brasil. Cachoeirinha, 2018.

TATSCH, R.; DEPONTI, C. M. O perfil dos produtores de arroz do Vale do Rio Pardo. In: VIII SEMINÁRIO INTERNACIONAL SOBRE DESENVOLVIMENTO REGIONAL. 8., 2017, Santa Cruz do Sul. Anais... Santa Cruz do Sul, Unisc, 2017.

USDA - FAS. World Agricultural Production. USA, 2018. Disponível em: https://apps.fas.usda.gov/psdonline/circulars/production.pdf. Acesso em: 10 mai. 2021. 